DISTRIBUTION STATEMENT A. Approved for public release; distribution is unlimited.

\title{
Coherence of Sound and Understanding Where it is Influenced in the Ocean
}

\author{
John Spiesberger \\ Scientific Innovations, Inc. \\ 6 Derringdale $\mathrm{Rd}$ \\ Radnor, PA 19087 \\ phone: (610) 225-2666 fax: (610) 225-2666 email: johnsr@sas.upenn.edu
}

Award Number: N00014-12-C-0230

\section{LONG-TERM GOALS}

The goal is to understand and reliably predict the temporal and spatial coherence of sound in the ocean due to influences from the sub-bottom, bottom, surface, and the sound speed and current fields in the fluid.

\section{OBJECTIVES}

The objective of this research is to develop software that accurately quantifies the spatial regions that influence the propagation of sound between a source and receiver in the ocean. Recent studies indicate that in some circumstances accurate predictions of temporal coherence can be made without knowing where the sound is being influenced (Spiesberger, 2011a,b). The present study will develop software to map where the sound is being influenced. Understanding where the sound is influenced will make it easier for scientists to develop theories to predict coherence. At very high acoustic frequencies, the regions that influence sound are shown by rays. Our research will develop software that shows the analogy of the ray path at all finite frequencies. Even moderately high frequencies are influenced by regions that are quite different than ray paths (Spiesberger, 2006b).

\section{APPROACH}

The maps where sounds are influenced between a source and receiver can be constructed by starting with the theory by Kirchoff and Raleigh from the 19th century (Born and Wolf, 1999). The approach uses openings in opaque screens to compute the received signal when the screen is placed anywhere between the source and receiver. Bowlin (1991) used this idea and showed that the regions of the ocean that influence sound for broadband signals are not given by the first Fresnel zone as some theories had assumed (Flatte et al, 1979). Spiesberger $(2005,2006 \mathrm{a})$ discussed subsequent problems associated with Flatte et al.'s theory to predict temporal coherence and developed an exact method for computing the regions of influence. In order to implement the approach, an approximate solution of the wave equation must be utilized that obeys reciprocity (Born and Wolf, 1999). Godin (1999) invented a parabolic approximation called OWWE that obeys reciprocity for media whose sound speed field varies in two spatial dimensions, normally with range and depth. Mikhin (2001) produced a numerical scheme to implement OWWE. In this contract, the regions of influence will be constructed through a 


\section{Report Documentation Page}

Form Approved

OMB No. 0704-0188

Public reporting burden for the collection of information is estimated to average 1 hour per response, including the time for reviewing instructions, searching existing data sources, gathering and maintaining the data needed, and completing and reviewing the collection of information. Send comments regarding this burden estimate or any other aspect of this collection of information,

including suggestions for reducing this burden, to Washington Headquarters Services, Directorate for Information Operations and Reports, 1215 Jefferson Davis Highway, Suite 1204, Arlington

VA 22202-4302. Respondents should be aware that notwithstanding any other provision of law, no person shall be subject to a penalty for failing to comply with a collection of information if it

does not display a currently valid OMB control number.

\begin{tabular}{|c|c|c|}
\hline $\begin{array}{l}\text { 1. REPORT DATE } \\
\text { 30 SEP } 2014\end{array}$ & 2. REPORT TYPE & $\begin{array}{l}\text { 3. DATES COVERED } \\
\mathbf{0 0 - 0 0 - 2 0 1 4} \text { to 00-00-2014 }\end{array}$ \\
\hline \multirow{3}{*}{\multicolumn{2}{|c|}{$\begin{array}{l}\text { Coherence of Sound and Understanding Where it is Influenced in the } \\
\text { Ocean }\end{array}$}} & 5a. CONTRACT NUMBER \\
\hline & & 5b. GRANT NUMBER \\
\hline & & 5c. PROGRAM ELEMENT NUMBER \\
\hline \multirow{3}{*}{\multicolumn{2}{|c|}{ 6. AUTHOR(S) }} & 5d. PROJECT NUMBER \\
\hline & & 5e. TASK NUMBER \\
\hline & & 5f. WORK UNIT NUMBER \\
\hline \multicolumn{2}{|c|}{$\begin{array}{l}\text { 7. PERFORMING ORGANIZATION NAME(S) AND ADDRESS(ES) } \\
\text { Scientific Innovations, Inc,6 Derringdale Rd,Radnor,PA,19087 }\end{array}$} & $\begin{array}{l}\text { 8. PERFORMING ORGANIZATION } \\
\text { REPORT NUMBER }\end{array}$ \\
\hline \multirow{2}{*}{\multicolumn{2}{|c|}{ 9. SPONSORING/MONITORING AGENCY NAME(S) AND ADDRESS(ES) }} & 10. SPONSOR/MONITOR'S ACRONYM(S) \\
\hline & & $\begin{array}{l}\text { 11. SPONSOR/MONITOR'S REPORT } \\
\text { NUMBER(S) }\end{array}$ \\
\hline
\end{tabular}

12. DISTRIBUTION/AVAILABILITY STATEMENT

Approved for public release; distribution unlimited

13. SUPPLEMENTARY NOTES

14. ABSTRACT

15. SUBJECT TERMS

16. SECURITY CLASSIFICATION OF:

\begin{tabular}{c|c|c|}
$\begin{array}{c}\text { a. REPORT } \\
\text { unclassified }\end{array}$ & $\begin{array}{c}\text { b. ABSTRACT } \\
\text { unclassified }\end{array}$ & $\begin{array}{c}\text { c. THIS PAGE } \\
\text { unclassified }\end{array}$
\end{tabular}

17. LIMITATION OF ABSTRACT

Same as

Report (SAR)

\begin{tabular}{c|l}
$\begin{array}{c}\text { 18. NUMBER } \\
\text { OF PAGES } \\
\mathbf{3}\end{array}$ & 19a. NAME OF \\
& \\
& \\
\end{tabular}


collaboration between Dr. Mikhin at Acacia Research and Dr. Spiesberger at Scientific Innovations, Inc.

\section{WORK COMPLETED}

We demonstrated last year that Dr. Mikhin's numerical implementation of OWWE obeys reciprocity to very high accuracy for broadband signals, even when the bottom is not flat and the speed of sound varies vertically and horizontally. In 2014, software was written to compute the regions of influence from the outputs of OWWE.

\section{RESULTS}

We demonstrated that the correct region of influence was obtained for a simple test case where the speed of sound was a constant.

\section{IMPACT/APPLICATIONS}

Ray theory has wide applications. The current approach for computing the regions that influence sound are exact at all finite frequencies. Although the current approach is much more computationally demanding than tracing rays, computers get faster and we believe that the exact approach will someday be widely used for the same reasons that ray theory is widely used.

\section{RELATED PROJECTS}

There is another approach for mapping where a medium affects the propagation of sound between a source and receiver. The method was invented by Marquering et al. (1999) who applied it to seismic problems. Sarsoulis and Cornuelle (2004) used Marquering's approach for application to underwater acoustics. If one wishes to map the regions in space that affect sound, the method we are using is valid at all orders, and Marquering's approach is valid to first order in the perturbations with respect to the reference state. The approaches are not identical in other respects and both offer valuable insights into where sound is influenced.

\section{REFERENCES}

Born M and Wolf E, Principles of Optics: Electromagnetic Theory of Propagation, Interference, and Diffraction (Cambridge: Cambridge University Press), 1999.

Bowlin, J., Generating eigenray tubes from two solutions of the wave equation, J. Acoust. Soc. Am., 89, 2663-2669, 1991.

Collins, M.D., Generalization of the Split-Step Pade, J. Acoust. Soc. Am. 96, 382-385, 1994.

Flatte S M, Dashen R Munk W, Watson K, and Zachariasen F., Sound Transmission through a Fluctuating Ocean\} (Cambridge: Cambridge University Press, Cambridge), 1979.

Godin, O.A., Reciprocity and energy conservation within the parabolic approximation, Wave Motion, 29, 175-194, 1999. 
Marquering H, Dahlen F A, and Nolet, G., Three-dimensional sensitivity kernels for finite-frequency traveltimes: the banana-doughnut paradox, Geophys. J. Int. 137, 805-15, 1999.

Mikhin, D., Energy-conerving and reciprocal solutions for higher-order parabolic equations, J. Computational Acoustics, 9, 183, DOI 10.1142/S0218396X01000450, 2001.

Sarsoulis E K and Cornuelle B D, Travel time sensitivity kernels in ocean acoustic tomography J. Acoust. Soc. Am., 116, 227-38, 2004.

Spiesberger, J.L., Locating where Transient Signals Travel in Inhomogeneous Media, http://www.arxiv.org/abs/physics/0501162, 31 Jan 2005.

Spiesberger, J.L., Regions where transient signals are influenced between a source and receiver, Waves in Random and Complex Media, 16, 1-21, $2006 a$.

Spiesberger, J.L., Regions that influence acoustic propagation in the sea at moderate frequencies, and the consequent departures from the ray-acoustic description, J. Acoust. Soc. Am., 120, 1842$1850,2006 b$.

Spiesberger, J., Internal Waves' role in Determining Probability Distribution of Coherent Integration Time near $133 \mathrm{~Hz}$ and $3709 \mathrm{~km}$ in North Pacific Ocean, IEEE J. Oceanic Engineering, 36, 760771, 2011a.

Spiesberger, J., Where the ocean influences the impulse response and its effect on synchronous changes of acoustic travel time, J. Acoust. Soc. Am., 130, 3642-3650, 2011 b.

Tappert, F., Spiesberger, J., and Boden, L., New full-wave approximation for ocean acoustic travel time predictions, J. Acoust. Soc. Am., 97, 2771-2782, 1995. 